\title{
Preparing Teachers to Teach in K-12 Blended Environments: A Systematic Mapping Review of Research Trends, Impact, and Themes
}

\author{
Cecil R. Short ${ }^{1}$ (D) Charles R. Graham $^{2}$ (D) Theresa Holmes $^{2} \cdot$ Laura Oviatt $^{2} \cdot$ Hannah Bateman $^{2}$
}

Accepted: 26 May 2021 / Published online: 4 July 2021

(C) Association for Educational Communications \& Technology 2021

\begin{abstract}
Despite evidence concerning the widespread growth of K-12 blended teaching and the impact that emergency remote teaching during the COVID-19 pandemic has had on the spread of K-12 online and blended teaching, we could find no systematic reviews focused on preparing K-12 teachers for blended teaching. Previous literature reviews, such as those from Halverson et al. (2012) and Drysdale et al. (2013), have noted the lack of research focused on K-12 blended teaching contexts. This systematic mapping review (Grant \& Booth, 2009) of 88 K-12 blended teacher preparation articles focused on identifying trends in author impact according to citation count and number of publications, journal impact according to number of publications, prevalence of research methods, and prevalence of research themes according to research questions and findings. The analysis provides a valuable snapshot of current literature, sets a foundation for a deeper thematic analysis of K-12 blended teacher preparation literature, and identifies some potential areas for future K-12 blended teaching research.
\end{abstract}

Keywords Blended learning $\cdot \mathrm{K}-12 \cdot$ Literature review $\cdot$ Professional development $\cdot$ Teacher education

\section{Introduction}

Graham (2019) noted that measuring the growth of blended teaching (BT) is difficult because institutions use different definitions of "blended" and lack ways to measure BT; additionally, instructors may choose to blend without the knowledge of administrators. Despite being difficult to measure, signs point toward the widespread growth of BT in K-12 contexts.

Cecil R. Short

cecil.r.short@gmail.com

Charles R. Graham

charles.graham@byu.edu

Theresa Holmes

theresapholmes@gmail.com

Laura Oviatt

oviattlaura@gmail.com

Hannah Bateman

hanbate22399@gmail.com

1 Texas Tech University, Lubbock, TX, USA

2 Brigham Young University, Provo, UT, USA
Gulosino and Miron (2017) found that enrollment in full-time K-12 blended schools increased from fewer than 2500 students in 2009 to over 25,000 students in 2014. As a response to BT growth, the United States (U.S.) 2017 National Education Technology Plan recommended "develop[ing] a teaching force skilled in online and blended instruction" (U.S. Department of Education, p. 40). Despite this national mandate, there is little peer-reviewed research focused on how to best prepare teachers for this emerging learning environment. BT is likely to see additional growth due to school investments in technological infrastructure, teacher professional development, and experience gained from emergency remote teaching that occurred during the COVID-19 pandemic.

Much of the research currently guiding K-12 blended teacher preparation is published in peer-reviewed book chapters and non-refereed white papers by organizations focused on BT and innovation. A 2012 review of high impact scholarship in BT found that 3.33\% (only two articles) of the topcited articles $(N=60)$ focused on K-12 settings (Halverson et al.). Similarly, a 2013 analysis of BT theses and dissertations found that only $8 \%$ of the studies focused on K-12 contexts (Drysdale et al.). A more comprehensive review of the literature noted important distinctions between BT in higher education and K-12 settings, stating that "adopters need 
refined implementation and evaluation frameworks as well as professional development and teacher education approaches that better meet the purposes and issues unique to blended learning in K-12 school" (Halverson et al., 2017, p. 55). A review of K-12 BT competencies also noted, "it was not so surprising to find a limited number of peer-reviewed articles in the literature around blended learning teaching competencies" and therefore included a large number of online resources and white papers from professional organizations in their analysis (Pulham \& Graham, 2018, p. 415).

Non-refereed online resources have been widely used to guide blended teacher preparation. Organizations such as the Michigan Virtual Learning Research Institute, the Christensen Institute, The Learning Accelerator, the Highlander Institute, the Blended Learning Universe, the Online Learning Consortium, the Evergreen Education Group, the Digital Learning Collaborative, iNACOL (now the Aurora Institute), ISTE, Lexia, Edutopia, ASCD, and Better Lesson have all provided resources focused on BT (see Table 1). A sample of such resources $(N=58)$ revealed that many focused on school or district-wide implementation of BT $(n=20)$, with much fewer focused on K-12 BT dispositions (2), readiness (2), evaluations (2), competencies (4), pedagogies (5), models (5), school profiles (5), reviews of BT literature (6), or teacher development (7). While many of these resources could guide BT preparation, more resources specifically focused on preparing teachers for BT are needed.

The lack of peer-reviewed resources for BT preparation combined with the call from the U.S. Department of Education to prepare teachers for BT suggests the need for a greater focus in the area. Additionally, we could find no systematic reviews of current peer-reviewed research for state departments of education, school districts, and university programs to reference in preparing K-12 teachers for BT. To better understand the current state of research focusing on the skills, knowledge, and practices that the growth of BT demands from $\mathrm{K}-12$ teachers, this systematic mapping review analyzes research trends in peer-reviewed articles focusing on preparation for K-12 BT.

\section{Review Questions}

1. How can the current state of K-12 BT research be characterized in terms of publication outlets, impact based on citation counts, and research methods?

2. To what extent has research revealed practices for preparing $\mathrm{K}-12$ teachers to teach in blended settings?

3. To what extent has research sought to define K-12 BT readiness?

4. To what extent have assessments or instruments been developed and used for measuring K-12 BT readiness?

\section{Methods}

We identified peer-reviewed journal articles from 2007 through 2019, using Academic Search Premier (EBSCO), Computers and Applied Sciences Complete (EBSCO), ERIC (EBSCO), PsycINFO (EBSCO), Teacher Reference Center (EBSCO), and SCOPUS. Graham (2016) suggested a process of iterative searches using various search terms when searching for BT literature because the "conversations are

Table 1 Examples of Online BT Resources for K-12 Contexts

\begin{tabular}{|c|c|c|}
\hline Focus/Theme & Source Organization & Name of Resource \\
\hline Implementation & $\begin{array}{l}\text { Michigan Virtual Learning Research } \\
\text { Institute }\end{array}$ & District-Level Blended Learning Implementation: Readiness Points and Challenges \\
\hline Implementation & Blended Learning Universe & We're Here Every Step of the Journey \\
\hline Implementation & iNACOL & $\begin{array}{l}\text { Mean What You Say: Defining and Integrating Personalized, Blended and Competency } \\
\text { Education }\end{array}$ \\
\hline Implementation & ISTE & Get Started with Blended Learning \\
\hline Implementation & Edutopia & Transitioning to Blended Learning \\
\hline Development & The Learning Accelerator & Partnering with a Local College to Develop New Teacher Training Opportunities \\
\hline Development & Christensen Institute & The Secret Element in Blended Learning \\
\hline Research & Christensen Institute & Is Higher Education Teaching Teachers to Blend? \\
\hline Profiles & The Learning Accelerator & See Schools in Action \\
\hline Models & Lexia & Four Keys to Success Using Blended Learning Implementation Models \\
\hline Pedagogies & ASCD & The Basics of Blended Instruction \\
\hline Competencies & iNACOL & iNACOL Blended Learning Teacher Competency Framework \\
\hline Evaluations & Digital Learning Collaborative & Does Blended Work? The 4Ps of Evaluating Your Blended Program's Effectiveness \\
\hline Readiness & Highlander Institute & Fuse RI District Readiness Survey \\
\hline
\end{tabular}


not taking place in one central location; they are distributed across many disciplines and scholarly communities" (p. 28). Our search included several iterations. Table 2 presents the refined search terms for the initial database searches.

Initial searches sought literature starting in 1999 because the year pre-dated Gulosino and Miron's (2017) data concerning enrollment in full-time blended schools by a full decade, which would allow for ample time in providing opportunities for research concerning BT knowledge, skills, and practices. The cut-off date of December 2019 was due to the start date of this research in early 2020. Early searches included terms for blended learning such as "hybrid," "station rotation," "lab rotation," and "flex," but these did not produce additional search results. Additionally, the search parameters initially considered search terms across multiple parameters, retrieving articles that seemed to have a preponderance of the terms. This search proved valuable but too exclusive. The final search revised the search terms, added additional parameters for each subject of the search, and applied related words when completing the search (see Table 3 ).

\section{Inclusion/Exclusion Criteria}

To be included in this review, research had to meet the following criteria:

1. Be published in English.

2. Be published in a peer-reviewed journal; it could not be published in trade journals, white papers, or book chapters.

3. Focus on intentionally preparing $\mathrm{K}-12$ teachers for BT modeling BT through professional learning experiences or university courses would not be considered sufficient for preparing K-12 teachers for BT unless the content of such courses and seminars focused on BT skills, knowledge, or practices.

4. The use of "blended" must refer to the strategic combination of online and in-person modalities (Graham, 2006).

\section{Outcomes of the Searches}

The initial search yielded 241 articles from EBSCO databases and 31 articles from Scopus. Of these articles, 11 were duplicates from both databases, leaving 261 articles to analyze for this review. SCOPUS yielded only one article included in the review that was not also in the EBSCO databases search. This article appeared in the EBSCO databses search during the final search, and therefore SCOPUS was not included as part of the more inclusive final search. Despite including research from 1999 onward, the earliest article in the review was from 2007. This finding is likely because blended learning, or hybrid learning, started in higher education before working its way to K-12 schools. The final search produced over 1600 results that we reviewed to uncover which articles would meet the inclusion/exclusion criteria. Of these results, 37 articles had already been accepted for the review from initial search. These articles were removed prior to further screening. Figs. 1 and 2 present the PRISMA flow diagrams (Page et al., 2021) for each of the searches.

Many articles used "blended" to describe teaching in two languages, teaching multiple subjects at once (e.g., math and science), or combining classes for in-service and pre-service teachers but did not include the strategic combination of online and in-person modalities. Because literature that did not focus on BT as the strategic combination of in-person and online instruction and K-12 teacher preparation could not answer the research questions, we excluded articles using "blended" in other ways. In the first search, these were excluded after retrieving full text copies of each article. Due to the larger volume of search results in the second search, these were excluded prior to retrieving full text articles. Also excluded from the final search prior to retrieving full text copies of each article were articles that did not focus on K-12 contexts (e.g., articles focused on using BT in schools of medicine).

Many of the articles from the initial and final searches focused on using BT for teacher preparation courses or professional training; however, they focused on developing inperson teaching skills rather than developing teachers' BT skills. While experiencing professional learning through blended learning might help prepare teachers to blend themselves, such modeling is unlikely to provide teachers with the additional knowledge and skills needed for BT. Such articles were only included if they presented evaluations of how the BT pedagogy affected teachers' perceptions of or plans for using BT.

Table 2 Initial Teacher Preparation for Blended Learning in K-12 Contexts Keyword Search

\begin{tabular}{|c|c|c|}
\hline & Subject & Keywords \\
\hline & $\mathrm{K}-12$ & "K-12” OR “K12” OR "secondary” OR “elementary" OR "high school” OR “middle school” OR "junior high" \\
\hline AND & Blended Learning & $\begin{array}{l}\text { "blended learn*" OR "blended teach*" OR "hybrid learn*" OR "hybrid approach" OR "flip*" OR "station rotation" } \\
\text { OR "lab rotation" OR "flex" }\end{array}$ \\
\hline AND & Teacher Preparation & $\begin{array}{l}\text { "teacher educat*" OR "teacher prepar*" OR "teacher professional development" OR "teacher training" OR "faculty } \\
\text { development" }\end{array}$ \\
\hline
\end{tabular}


Table 3 Final Revised Keyword Search

\begin{tabular}{|c|c|c|c|}
\hline & Subject & Keywords & Parameter \\
\hline & $\mathrm{K}-12$ & $\begin{array}{l}\text { "K-12" OR “K12” OR “secondary" OR "elementary" OR "high school” OR "middle school” } \\
\text { OR "junior high" OR "teacher*”" }\end{array}$ & Abstract \\
\hline AND & Blended Learning & "blend*” OR “flip*” & Subject \\
\hline AND & Teacher Preparation & "prepar*” OR “course*” OR “develop*” OR “training" & Abstract \\
\hline
\end{tabular}

After applying the criteria above, we selected 88 articles for this trend analysis. These 88 articles were analyzed and categorized based on the insights they provided for the research questions.

\section{Analysis Process}

We used content analysis techniques (Krippendorff, 2004) to identify patterns in the articles' research questions, methods, and findings. By uncovering patterns in research methods and topics of study, we were able to synthesize findings across sources to illustrate the current state of research in this area and to suggest areas for development. This method of analysis aligns with the methods of a "mapping review" as suggested by Grant and Booth (2009) in that it attempts to characterize a set of literature based on its key features. Such reviews provide a contextualization of research within an established group of literature and can lay the foundation for further indepth reviews of literature. Studies from the 88 articles included (a) literature reviews and general descriptions of blended learning meant to provide context for K-12 BT research and practice, (b) design and descriptive studies of university coursework and professional development for BT preparation, (c) descriptions of competencies and implementation practices used to guide BT preparation, and (d) instruments for measuring aptitude related to BT (see Fig. 3). Despite these organizing themes, our analysis suggests that additional research in each of these areas can better specify practices and frameworks for guiding teacher preparation. Additionally, the analysis identified the outlets most commonly used to share research in K-12 BT, the impact of research based on citation counts, and the methods used for such research.

\section{Methodological Limitations}

This study's limitations included the databases used for research, the search terms used, and the exclusion of nonrefereed resources. We feel that the databases used to gather articles for analysis represent reliable sources for K-12 BT research; however, K-12 BT conversations take place in many publication locations, making some niche research challenging to locate. Such challenges are further exacerbated by the many terms used to reference BT, its practices, implementations, and its contexts, especially within
Fig. 1 PRISMA Flow Diagram for the Initial Literature Search

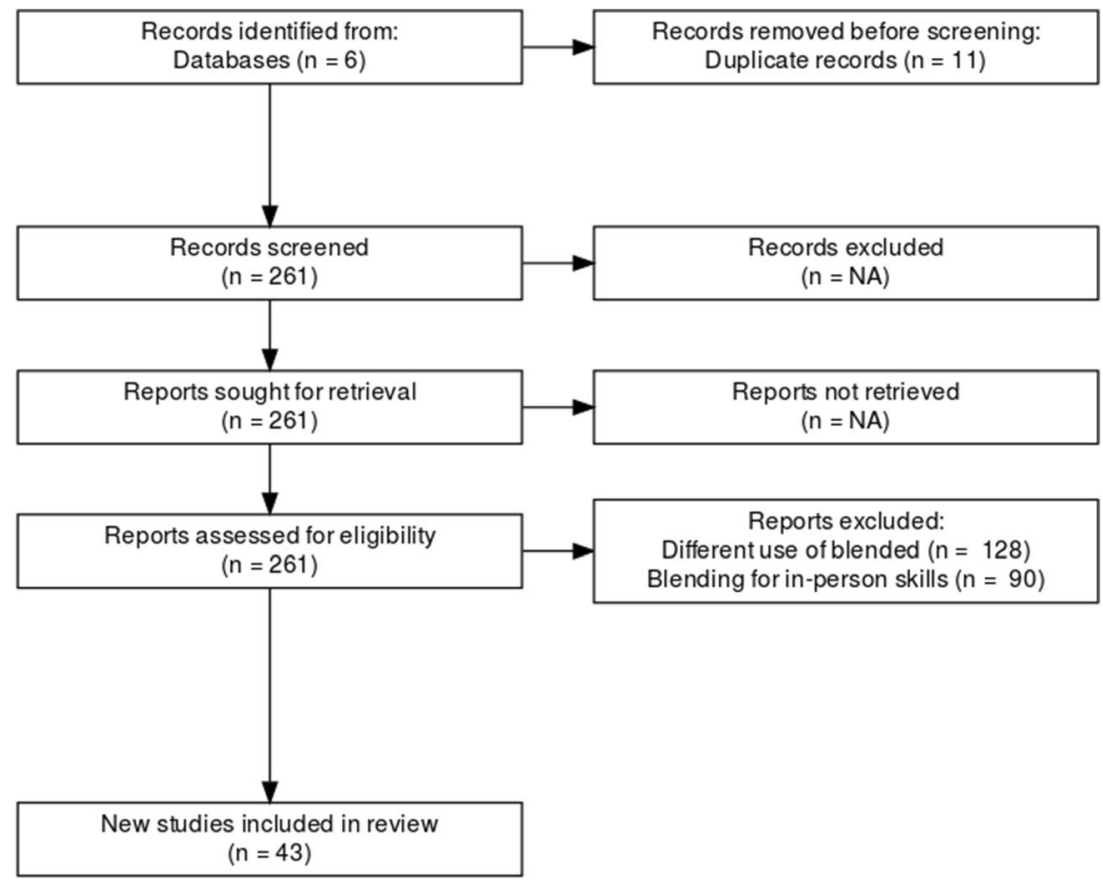




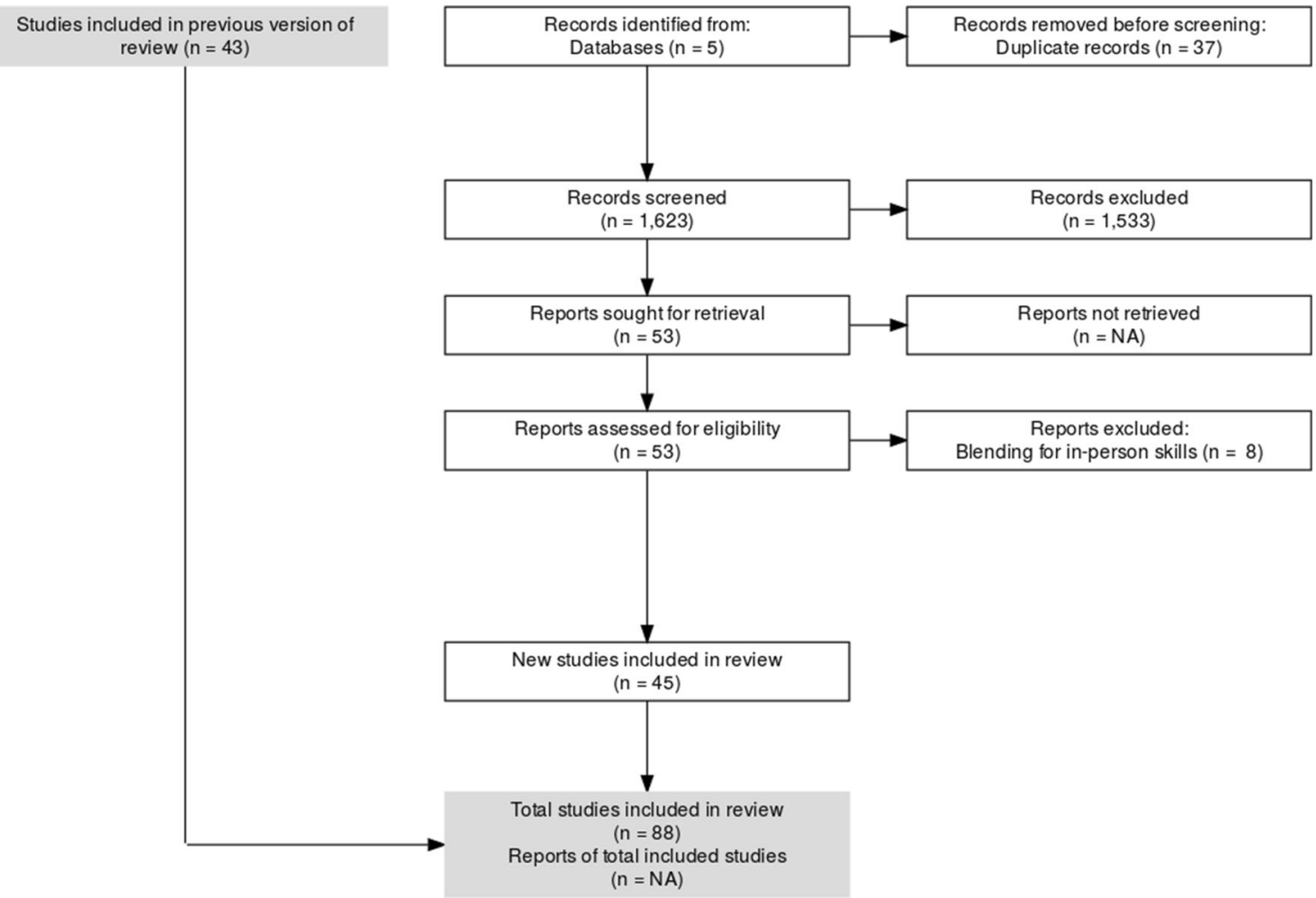

Fig. 2 PRISMA Flow Diagram for the Final Search

international research. This led to the inclusion of specific BT models as part of the search terms. If articles were not direct in connecting their findings to BT preparation, there is a possibility that we could have overlooked them as part of our search. Despite this challenge, we feel confident in our search terms' iterations and our searches' ability to produce relevant literature. Lastly, while we provide a needed analysis of peerreviewed research, there are many non-refereed resources in this area that are not part of our investigation. Researchers seeking to situate their research within the ongoing conversation of K-12 BT would be wise to remember that many conversations are happening outside of peer-reviewed journals.

\section{Findings}

The following sections detail the findings of our analyses according to the research questions. The first section details
Fig. 3 Categorization of Literature According to Broad Themes
50

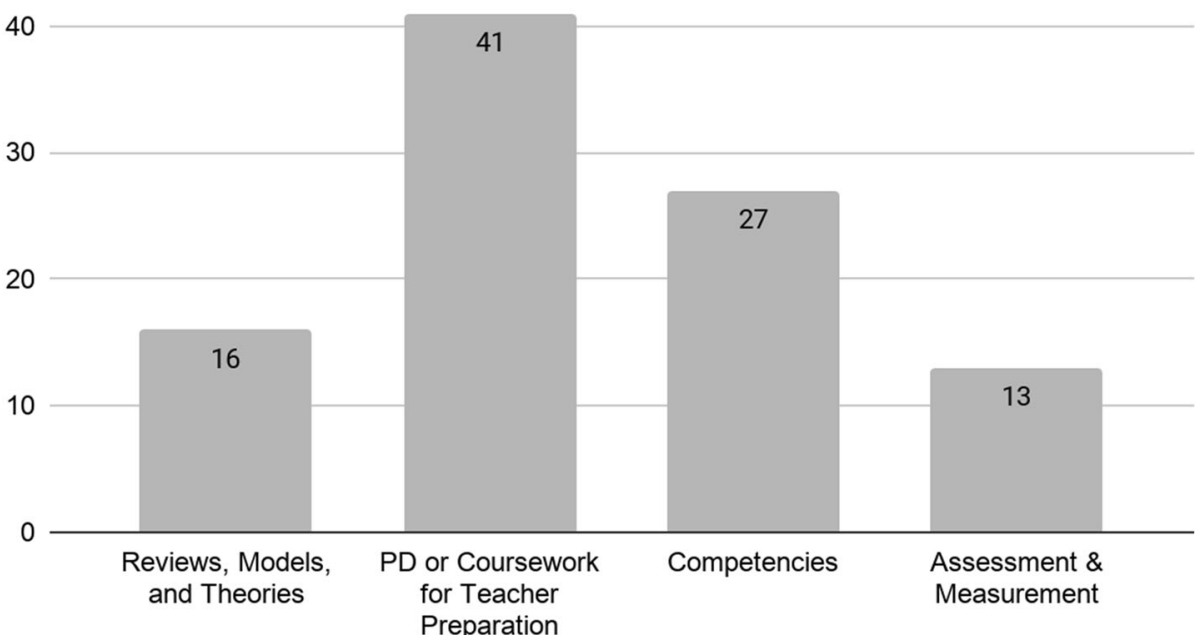


publication outlets, demonstrating that a central location for K-12 BT research has begun to emerge, the impact of authors and articles according to citation count, and the various methods used to approach K-12 BT research questions. The second section details findings related to research that focused on reviews, models, and theories of K-12 BT research to pave the way for future research and practice. The third section identifies themes focused on preparing teachers for BT through university coursework or professional development. The fourth section details findings related to research focused on identifying competencies needed for effective BT. The final section details findings related to research focused on K-12 BT readiness and evaluation. Figure 3 provides an overview of how many articles from our analysis are in each category discussed in the second through fifth sections. Some articles appear in more than one category due to the breadth of the research or findings.

\section{Publication Outlets, Impact, and Research Methods}

Most of the articles in our review were published during or after 2016 (see Fig. 4), and 40.9\% ( $n=36)$ of the articles were from international contexts, either authored by international researchers or focusing on international contexts. Such diversity may account for where research is published. Multiple articles came from Australia $(n=4)$, Belgium (3), China (2), Greece (4), India (2), New Zealand (2), Spain (2), Taiwan (2), Turkey (3), and the United Kingdom (2), with one article each from Bahrain, Egypt, Italy, Japan, Kuwait, Malaysia, Norway, Portugal, Saudi Arabia, Serbia, South Korea, and the United Arab Emirates.

There was a considerable rise in publications in 2016, which may be due to the creation of The Journal of Online Learning Research (JOLR), which began publishing in 2015 and specifically publishes K-12 online and blended learning research. JOLR produced the most articles in our review at 13, with one article published in 2015, four in 2016, one in 2017, two in 2018, and five in 2019. As shown in Table 4, four journals published four articles each, and nine journals published two articles each. The other 42 journals cited as part of this review only produced one article each.

\section{Article and Author Impact}

Despite producing the most articles for our review, JOLR did not produce any of the top-cited articles. Table 5 lists the topcited articles from the review. The articles were published in both international and North American journals from 2008 to 2018. There were no repeated contributions by authors within the top twenty articles. Only seven of the top-cited articles were published within the last five years, 10 were published between the years of 2011-2015, and three articles were published from 2008 to 2010 . Our review identified that international articles contributed 11 of the top twenty articles and eight of the top ten. The top-performing journal was The Journal of Technology and Teacher Education (JTATE), with four articles in the top 20, followed by Computers and Education with three articles.

The order of the top 20 cited articles would change significantly if measured by average citations per year. Basal (2015) would remain the top-cited article but be followed by Foulger et al. (2017). Kurt (2017) would move from the 9th position to the 4th position, followed by El-Deghaidy and Nouby (2008), which would move from the 2 nd to the 5 th position. One of the significant moves would be Pulham and Graham (2018), moving from the 19th to the 11 th position. By positioning articles by average citations per year, articles published within the last five years would move to higher positions, showing

Fig. 4 Years of Publication

20

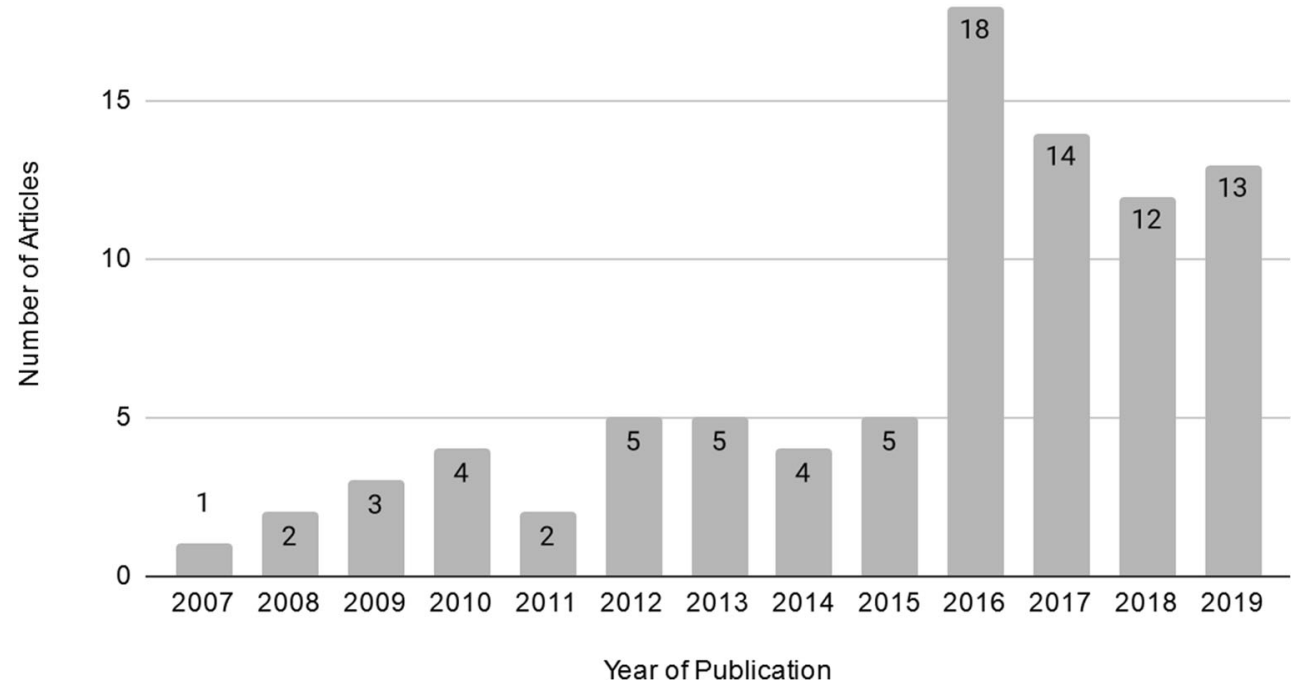


Table 4 Top Publishers of Articles in Our Review

\begin{tabular}{ll}
$\begin{array}{l}\text { No. of } \\
\text { Publications }\end{array}$ & Journal Name \\
\hline 13 & Journal of Online Learning Research \\
4 & Australasian Journal of Educational Technology \\
4 & Computers \& Education \\
4 & Contemporary Issues in Technology and Teacher \\
4 & Education \\
2 & Journal of Technology and Teacher Education \\
2 & Contemporary Educational Technology \\
2 & International Journal of Research in Education and \\
2 & Science \\
2 & Journal of Educational Technology \& Society \\
2 & Journal of Information Technology Education: \\
2 & Research \\
2 & Journal of Research on Technology in Education \\
2 & Teaching \& Teacher Education \\
\hline
\end{tabular}

the impact they have had in the few years they have been published.

\section{Research Methods}

Of the top 20 articles, seven articles used a combination of research methods, five presented models and theories, five presented literature review articles, and two solely used qualitative methods. All of the articles that used a combination of approaches used qualitative methods, making qualitative analysis the most common method overall. This trend was typical of all 88 articles (see Fig. 5). Table 6 describes the various research methods identified in the articles.

Figure 5 demonstrates the prevalence of research methods employed throughout all the articles. Qualitative approaches were employed in 52 of the 88 articles, with 28 of those solely using qualitative approaches and 24 combining qualitative analysis with quantitative methods. Most of the articles $(n=$ 30) used a combination of approaches in their research. Six of these articles used descriptive and inferential methods, 14 used descriptive and qualitative methods, four used inferential and qualitative methods, and six used all three approaches.

\section{Author Impact}

We awarded each author one point for a first authorship and a half-point for secondary authorships. These point totals were multiplied by the number of citations for the articles in which they were listed as an author. This method of calculating impact has been used in previous BT literature reviews (see Halverson et al., 2012). For example, Charles R. Graham had one first authorship with 14 citations and three secondary authorships with eight, 14, and 46 citations. He received 14 points for the first authorship and a combined 34 points for his secondary authorships for a total of 48 author points. Figure 6 shows the authors who received 100 or more author points.

A total of 183 authors contributed to the articles in this review. International authors are well represented in the top authors, with the top two being from international contexts as well as nine of the top thirteen. Most of the authors on the topranked author list contributed only one article for which they were the primary author. Philipsen, however, ranked sixth, contributed three publications as the first author. Nouby contributed two articles, both as a secondary author, including a co-authorship with El-Deghaidy, ranked second. Mouzakis and Qasem both contributed two articles as the first author. The author with the highest author points was Ahmet Basal from Turkey earning 260 points from the top-cited article (see Table 5), for which he was the first author. Philipsen and Qasam are the only authors to earn more than 100 author points who did not author a top-cited article.

While total citations can measure an author's impact, it is also important to note how many authors had multiple authorships. Of the 183 authors present in our review, only 19 authored more than one article. Of those 19, six had at least two first authorships, with Philipsen being the only author with three first authorships. However, the authors with the most authorships were Graham, and Borup, who both had four articles in our review. Table 7 lists the authors who had more than one authorship and their authorship position.

\section{Reviews, Models, and Theories}

Of the 88 articles, five articles were literature reviews, and 11 presented models and theories to guide implementation or further research. Loncar et al. (2014) presented a literature review focused on the uses of asynchronous online discussions across $\mathrm{K}-12$ and higher education settings. Like Halverson et al. (2012) and Drysdale et al. (2013), Loncar et al. (2014) found that there was a lesser focus on K-12 contexts than on higher education contexts but presented a less stark contrast $-21 \%$ of research focused on K-12 with the remainder focusing on higher education. Oliver and Stallings (2014) similarly noted in their review that "the bulk of articles referenced in this review are based in higher education, [but] the teaching considerations are generally applicable to K-12 blended learning" (p. 59). Parks et al. (2016) highlighted BT's social desirability and suggested that current professional development (PD) may not accurately measure such training's effectiveness. This suggestion is important, as Green and Hale's (2017) thematic analysis of research on K12 online and blended learning found that "there is a substantial need for teachers who are prepared to best facilitate learning that lives up to the potential of both modes of education," 
Table 5 Top Ranked Articles as Measured by Citation Count

$\begin{array}{lllll}\text { \# } \begin{array}{lll}\text { Total } \\ \text { cites } & \begin{array}{l}\text { cites/ } \\ \text { yr }\end{array}\end{array} & \text { Year Authors } & \text { Title } & \text { Source } \\ & & & \end{array}$

\begin{tabular}{lllll}
\hline 1 & 260 & 43.33 & 2015 & Basal \\
2 & 249 & 19.15 & 2008 & $\begin{array}{c}\text { El-Deghaidy and } \\
\text { Nouby }\end{array}$ \\
3 & 240 & 26.67 & 2012 & $\begin{array}{c}\text { Rosen and Beck-Hill } \\
\text { Rosen }\end{array}$
\end{tabular}

The Implementation of a Flipped Classroom in Foreign Language Teaching

Effectiveness of a Blended e-Learning Cooperative Approach in an Egyptian Teacher Education Programme

Intertwining Digital Content and a One-to-One Laptop environment Journal of Research on in Teaching and Learning: Lessons from the Time to Know Program

$4 \quad 175 \quad 14.58 \quad 2009$ Karasavvidis

Activity Theory as a Conceptual Framework for Understanding Teacher Approaches to Information and Communication Technologies

5152192013 Jimoyiannis, Tsiotakis, Roussinos and Siorenta

$612832 \quad 2017$ Foulger, Graziano, Schmidt-Crawford and Slykhuis $\begin{array}{llll}7 & 119 & 13.22 & 2012 \quad \begin{array}{c}\text { Alayyar, Fisser, and } \\ \text { Voogt }\end{array}\end{array}$

$8114 \quad 16.292014$ Loncar, Barrett, and Liu

$9 \quad 95 \quad 23.75 \quad 2017 \quad$ Kurt

$1091 \quad 18.2 \quad 2016$ Hao and Lee

$11 \quad 84 \quad 12 \quad 2014$ Oliver and Stallings

$1273 \quad 14.6 \quad 2016$ Chen

$1361 \quad 5.55 \quad 2010$ Bjekic, Krneta, and Milosevic

$1453 \quad 7.57 \quad 2014$ Archambault, DeBruler, and Freidhoff

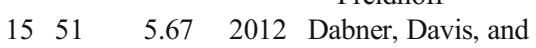
Zaka

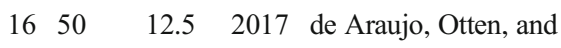
Birisci

$\begin{array}{llll}17 & 47 & 3.62 \quad 2008 \text { Mouzakis }\end{array}$

18465.752013 Basham, Smith, Greer, and Marino

$1941 \quad 13.672018$ Pulham and Graham 2040102017 Song, Jong, Chang, and Guest Editorial: "HOW" to Design, Implement and Evaluate the Chen
Preparing Teachers to Integrate Web 2.0 in School Practice: Toward a Framework for Pedagogy 2.0

Teacher Educator Technology Competencies

Developing Technological Pedagogical Content Knowledge in Pre-Service Science Teachers: Support from Blended Learning

Towards the Refinement of Forum and Asynchronous Online Discussion in Educational Contexts Worldwide: Trends and Investigative Approaches within a Dominant Research Paradigm

Implementing the Flipped Classroom in Teacher Education: Evidence from Turkey

Teaching in flipped Classrooms: Exploring Pre-Service Teachers' Concerns

Preparing Teachers for Emerging Blended Learning Environments

Impacts of Flipped Classroom in High School Health Education

Teacher Education from E-Learner to E-Teacher: Master Curriculum

K-12 Online and Blended Teacher Licensure: Striking a Balance Between Policy and Preparedness

Authentic Project-Based Design of Professional Development for Teachers Studying Online and Blended Teaching

Mathematics Teachers' Motivations for, Conceptions of, and Experiences with Flipped Instruction

Teachers' Perceptions of the effectiveness of a Blended Learning Approach for ICT Teacher Training

The Scaled Arrival of K-12 Online Education: Emerging Realities and Implications for the Future of Education

Comparing K-12 online and blended teaching competencies: A lit-

Flipped Classroom? - A Synthesis
Turkish Online Journal of Distance Education

Computers \& Education

Technology in Education

Computers \& Education

Australasian Journal of Educational Technology

Journal of Technology \& Teacher Education

Australasian Journal of Educational Technology

Computers \& Education

Journal of Educational Technology \& Society

Computers in Human Behavior

Journal of Technology \& Teacher Education

Journal of Educational Technology Systems

Turkish Online Journal of Educational Technology

Journal of Technology and Teacher Education

Contemporary Issues in Technology and Teacher Education

Teaching and Teacher

Journal of Technology \& Teacher Education

Journal of Education

Distance Education

Journal of Educational Technology \& Society Education asserting that both in-service and pre-service teachers "must have opportunities for meaningful PD in the arena of blended and fully online curriculum design, pedagogy, and facilitation" (p. 147). Lastly, Hu et al. (2019) analyzed the 51 articles published in JOLR from 2015 to 2018, and confirmed JOLR as a center for research focused on K-12 BT.
The 11 articles focused on providing models, theories, and definitions for guiding BT preparation and implementation had various approaches to the same challenges. Eisenbach (2016), Hoskins (2011), Jimoyiannis et al. (2013), and Song et al. (2017) all noted the changes to traditional practices that must occur to implement BT. Jimoyiannis et al. (2013) 
Table 6 Description of Research Methods

\begin{tabular}{|c|c|c|}
\hline Method & Description & Methods/Characteristics \\
\hline Descriptive & Used descriptive statistics & Mean, median, standard deviation, count, averages \\
\hline Inferential & Used inferential statistics & $\begin{array}{l}\text { Experiment, causal, correlation, ANOVA, Chi-Square, t-tests, } p \text { value, } \\
\text { factor analysis, component analysis }\end{array}$ \\
\hline Qualitative & Used interpretive and descriptive qualitative analysis & $\begin{array}{l}\text { Case study, naturalistic inquiry, interview, focus group, open-ended } \\
\text { survey, quote, phenomenology, ethnography, interpretative lens }\end{array}$ \\
\hline Lit Review & $\begin{array}{l}\text { Focused on introducing or explaining the extent of prior } \\
\text { blended learning research through an analysis of literature }\end{array}$ & $\begin{array}{l}\text { Tendency to focus on blended learning trends or research in a general } \\
\text { sense, as opposed to specific contexts or developments }\end{array}$ \\
\hline Model/Theory & $\begin{array}{l}\text { Suggested, extended, or applied a theory thoroughly, } \\
\text { including implementation practices }\end{array}$ & $\begin{array}{l}\text { Exclusion of frameworks merely cited to provide background or } \\
\text { context }\end{array}$ \\
\hline Combination & $\begin{array}{l}\text { Used more than one kind of empirical data analysis (i.e., } \\
\text { descriptive, inferential, or qualitative methods). }\end{array}$ & Any multiplicity of data analysis, regardless of which or how many \\
\hline
\end{tabular}

explained that integrating Web 2.0 resources into the classroom requires a pedagogical strategy shift. Song et al. (2017) provided illustrations of some of these shifts when transitioning to flipped instruction. Hoskins (2011) noted that leaders of distance and continuing education who already understand the process of transitioning away from traditional inperson teaching need to support K-12 efforts in such shifts. Basham et al. (2013) and Holland and Piper (2016) made similar calls for leadership in BT implementation. Basham noted that "leadership is required if online and blended learning is to meaningfully impact education" (p. 57).

One reason leadership is seen as essential to implementing BT is that many teachers seem to have insufficient knowledge or resources to learn how to blend independently. Hadjiathanasiou (2009) noted teachers believed the implementation of BT required more preparation time than they were used to and such time would be a deterrent to many of them. Lewis and Dikkers (2016) supported this notion, noting that many teachers felt that continued training was needed to implement BT even after receiving professional development. This determination seems to be a fairly universal experience for K-12 teachers, as Kundu (2018) noted a similar phenomenon with BT implementation in Indian elementary schools. Duhaney (2012) suggested that using BT in teacher preparation courses could help new teachers understand how to implement it in their future classrooms. Graziano and Bryans-Bongey's (2018) survey of 215 leaders of teacher education programs found that change within these programs is complicated due to the high demands already placed on teacher education.

\section{University Coursework and Professional Development}

Figure 7 illustrates the categorization of the 43 articles focused on using PD or university coursework to prepare teachers for BT. There were three methods used to prepare teachers for BT. The first was to have university coursework intentionally focused on preparing teachers for BT. Second, some teacher preparation courses used $\mathrm{BT}$ as a teaching method and then
Fig. 5 Research Methods Employed

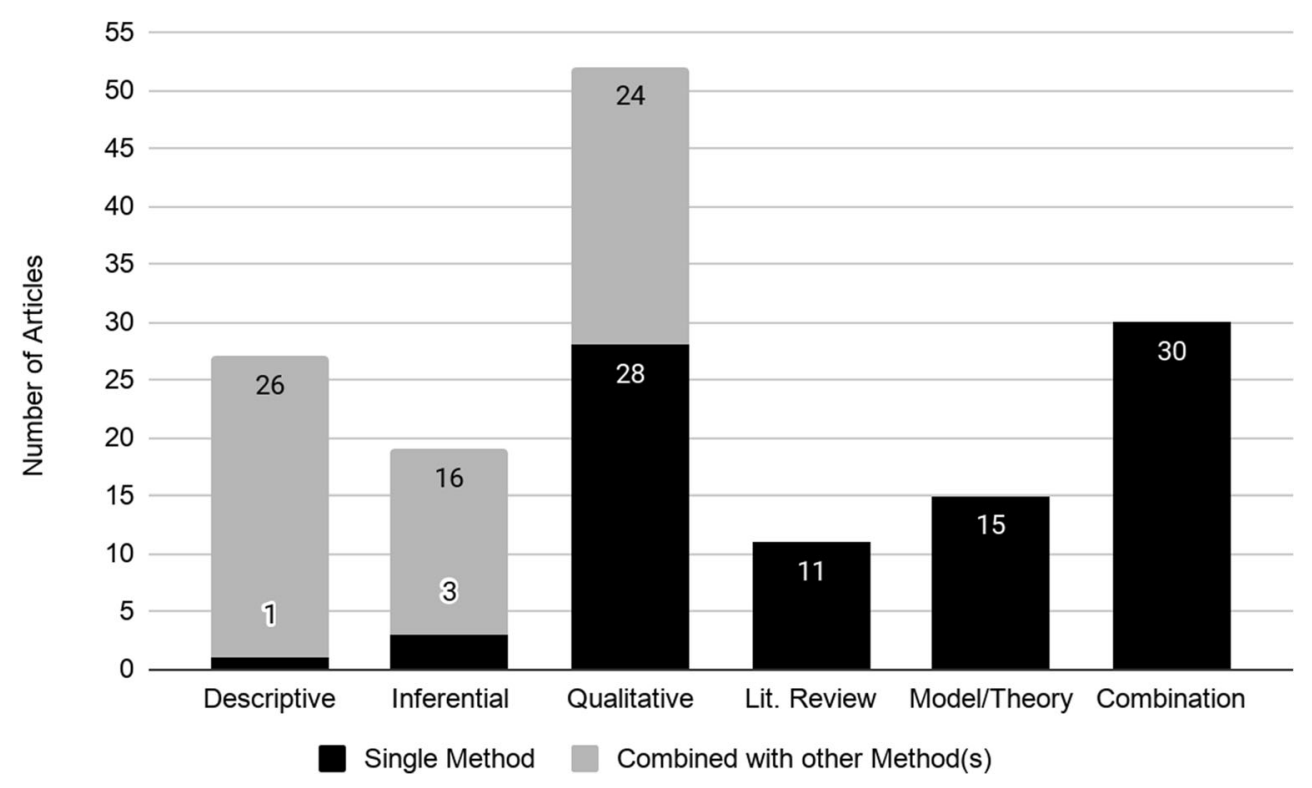


Fig. 6 Top Authors According to Author Points
300

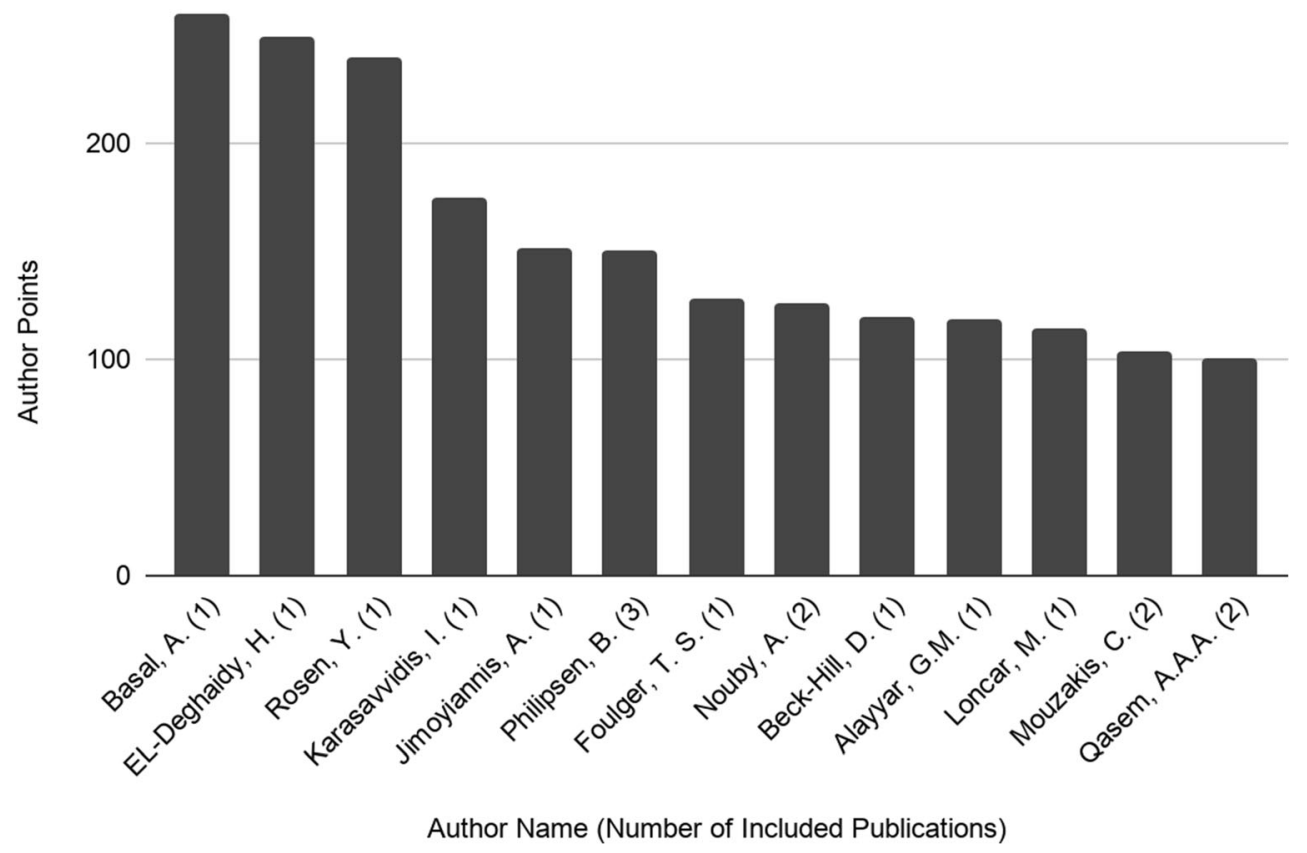

evaluated how it impacted teachers' perceptions of and plans for BT. Lastly, 21 articles focused on the impacts of PD on BT readiness.

Table 7 Authors with Multiple Publications

\begin{tabular}{llll}
\hline $\begin{array}{l}\text { Total } \\
\text { Publications }\end{array}$ & Author Name & $\begin{array}{l}\text { Primary } \\
\text { Authorship }\end{array}$ & $\begin{array}{l}\text { Secondary } \\
\text { Authorship }\end{array}$ \\
\hline 4 & Charles R. Graham & 1 & 3 \\
4 & Jered Borup & - & 4 \\
3 & Brent Philipsen & 3 & - \\
3 & Emily B. Pulham & 2 & 1 \\
3 & Jo Tondeur & - & 3 \\
2 & Charalambos Mouzakis & 2 & - \\
2 & Arwa Ahmed Abdo & 2 & - \\
2 & Qasem & 2 & - \\
2 & Kristen Shand & 2 & - \\
2 & Mark Stevens & 1 & 1 \\
2 & Karen Arnesen & 1 & 1 \\
2 & Kevin J. Graziano & 1 & 1 \\
2 & Pinelopi Zaka & - & 2 \\
2 & Michael K. Barbour & - & 2 \\
2 & Susan Glassett Farrelly & - & 2 \\
2 & Ahmed Nouby & - & 2 \\
2 & Cecil R. Short & - & 2 \\
2 & Silke Vanslambrouck & - & 2 \\
2 & Gandla Viswanathappa & - & 2 \\
\hline & Chang Zhu & & \\
\hline
\end{tabular}

\section{University Coursework}

The 14 articles focused on BT coursework had a few thematic similarities. For example, Alayyar et al. (2012) and Turvey (2010) sought to provide frameworks for BT preparation. Turvey (2010) provided a framework for helping teachers develop their BT skills beyond the scope of a single course through reflections, while Alayyar et al. (2012) used Mishra and Koehler's (2006) TPACK framework to build BT skills with pre-service science teachers. Bromley et al. (2014), Daum and Woods (2015), El-Deghaidy and Nouby (2008), and Piotrowski and Witte (2016), also provided research focused on BT preparation within content-specific methods courses - literature, physical education, science, and English, respectively. It was more common for articles to focus on courses geared explicitly toward BT preparation. Some of these courses were for undergraduate pre-service teachers (Arnesen et al., 2019; Luo et al., 2017; Shand \& Farrelly, 2017; Shand \& Farrelly, 2018; Zhang, 2010), while others had a focus on graduate-level courses (Dabner et al., 2012; García-Sánchez \& Santos-Espino, 2017; Kennedy \& Hinkley, 2009; Walta \& Nicholas, 2013). Most of these articles reported that students had positive perceptions of BT and would be comfortable implementing some aspect of BT in their classrooms.

\section{Modeling BT in University Coursework}

Six articles examined the use of BT for in-person teaching strategies but included some evaluation of how the BT 
Fig. 7 Categorization of Articles Focused on BT Preparation
25

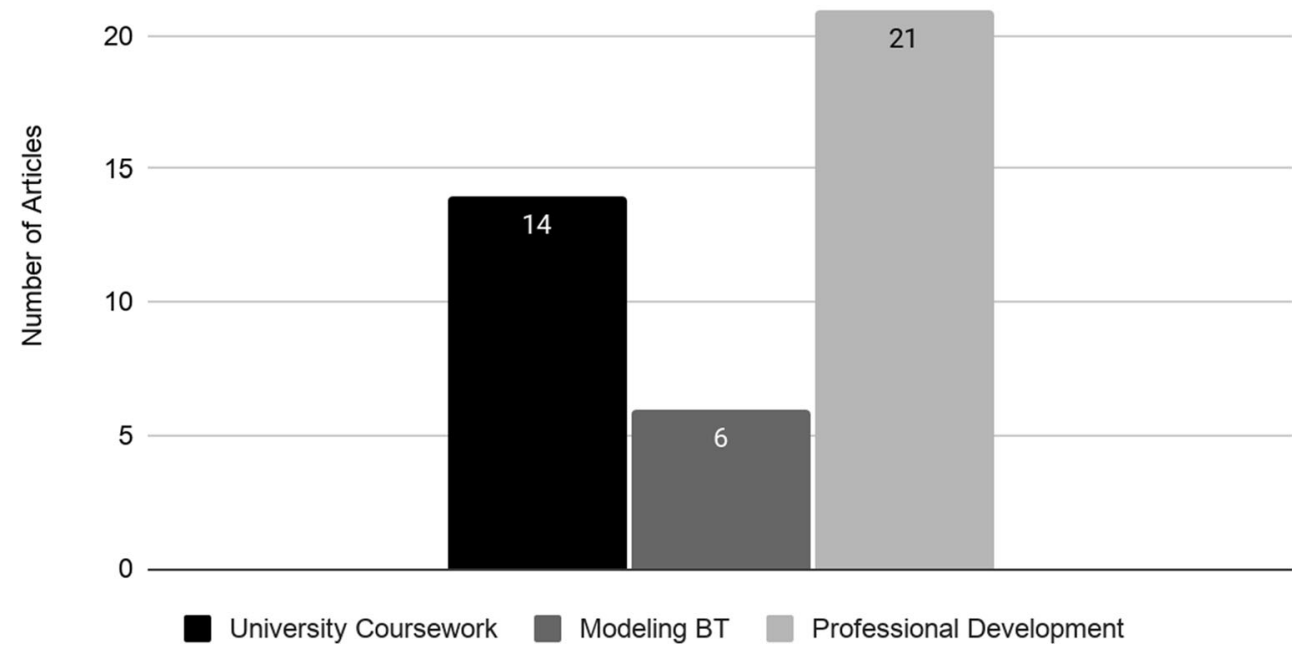

impacted teachers' perceptions of BT and plans for BT implementation. For example, Crawford and Jenkins (2018) found that pre-service music teachers in a team teaching and BT context responded positively to the BT, with some teachers choosing to emulate the BT in their future classrooms. Kurt (2017) experienced similar findings with pre-service English teachers in Turkey. Other researchers focused on how specific BT tools impacted teachers' perceptions of BT. Doğan and Gülbahar (2018) investigated uses and perceptions of social media for BT. Donne (2012) took a similar approach to wikis. Lastly, Karasavvidis (2009) and Lee and Martin (2019) analyzed teacher's use of computersupported collaborative learning and computer-assisted language learning, respectively, to understand how teachers' experiences with technological and pedagogical activities impacted their perceptions and plan to use such approaches in their future classrooms. Both articles identified benefits to their BT approaches that teachers wanted to implement in the future.

\section{Professional Development for BT}

Twenty-one articles focused on using PD to provide teachers with the training needed to implement BT. Many of these articles described various models for preparing teachers for BT. Some of these models used online training components to model BT practices (Al-Doseri et al., 2016; Lim, 2017; Mouzakis, 2008; Mouzakis et al., 2010; Wayer et al., 2015; Zhou et al., 2007; Ziegenfuss et al., 2019) and others combined both online and in-person training (Rieckhoff et al., 2018). Other models presented programs and evaluations of programs for preparing teachers for BT (Moore et al., 2017; Philipsen, 2019; Philipsen, Tondeur, Pareja Roblin, et al., 2019a; Philipsen, Tondeur, Pynoo, et al., 2019b; Puhala,
2018; Qasem \& Viswanathappa, 2016a; Stevens et al., 2018). These articles highlight important characteristics to consider when planning PD for BT.

Other articles were more specific in their PD focus. For example, Azukas (2019) focused on PD for personalized learning, Bjekic et al. (2010) focused on the new roles that BT requires, and Goodnough and Murphy (2017) focused on flipped instruction. Some articles also focused on PD for specific BT tools, such as mobile technology (O'Sullivan \& Seabra, 2016) or a particular learning platform (Papadakis et al., 2012). Regardless of focus, these articles provide valuable insights for researchers and practitioners seeking to lead PD for BT, and most incorporated some level of evaluation of their PD and suggestions for future research and implementation.

\section{Competencies for BT}

The competencies used to guide teacher preparation for BT fell into three categories: (1) competencies derived from research/theory, (2) competencies derived from BT practices, and (3) competencies derived from the process of implementing BT. Figure 8 illustrates article distribution among these categories. Most of the articles either presented competencies derived from examples of BT practices or experiences with BT implementation. The remaining articles derived competencies from reviews of research or theoretical foundations.

\section{Research/Theory-Derived Competencies}

Seven articles focused on BT competencies derived from research or theory. Some articles were broad in their focus, such as Foulger et al. (2017), which provided 12 technology- 
Fig. 8 Categorization of Articles Focusing on BT Competencies

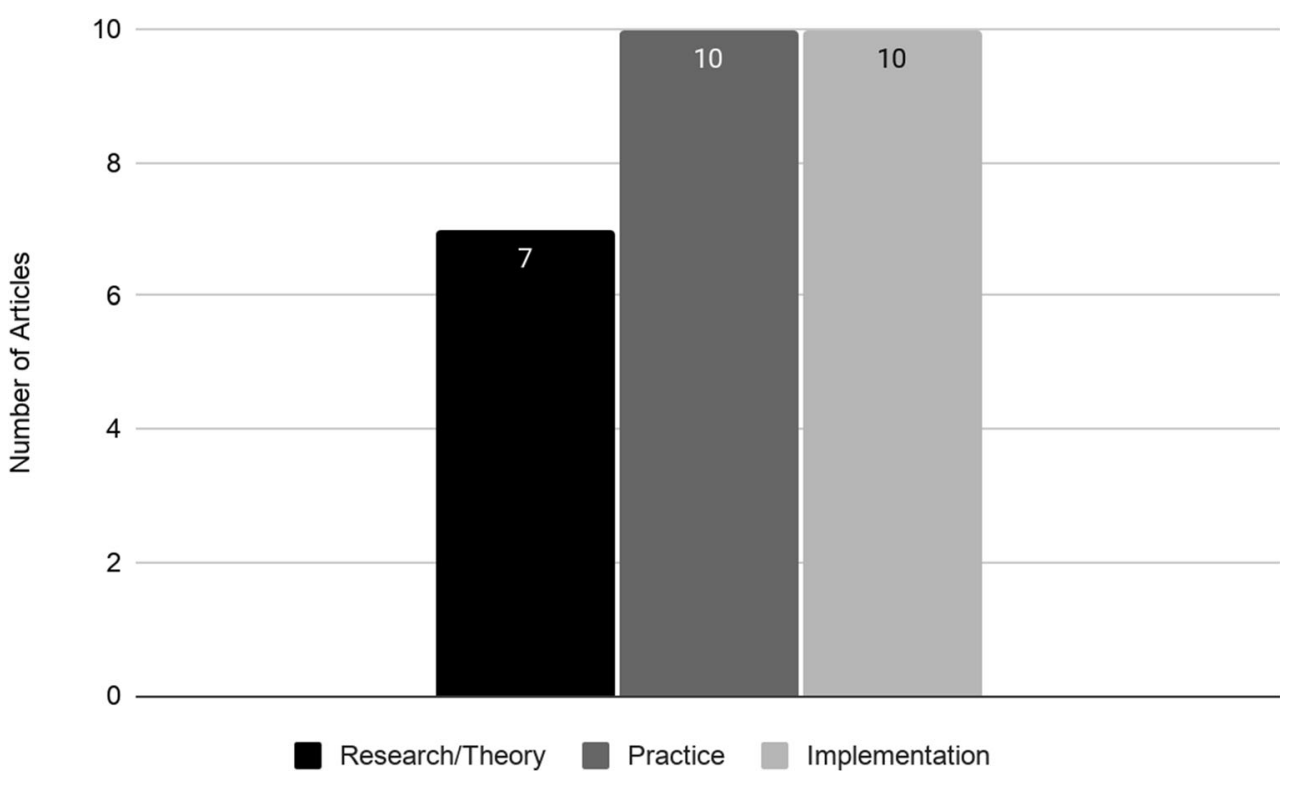

focused teacher competencies - a few directly related to BT. Others, such as Oliver and Stallings (2014,) Pulham and Graham (2018), and Pulham et al. (2018), provide syntheses of existing competency frameworks to identify competencies pertinent to BT. The remaining articles took different approaches toward BT competencies. Al-Doseri et al. (2016) provided an overview of competencies created to lead their PD efforts. Archambault et al. (2014) provided an analysis of state policies related to online and blended learning, highlighting the competencies that states expect teachers to develop for BT. Bjekic et al. (2010) focused on developing a curriculum that provides teachers with the skills needed for various roles they must fulfill in BT. In all cases, these competencies help create a theoretical framework for designing coursework or PD for BT preparation.

\section{Practice-Derived Competencies}

Ten articles derived competencies from researching established BT practices. Two of these studies compared traditional teaching practices to BT to demonstrate how traditional best practices can still be applied to BT (Anthony, 2019) but that BT allows for more adaptive approaches to instruction (Rosen \& Beck-Hill, 2012). Basal (2015), Shaffer (2016), and Webel et al. (2018) all focused on the competencies needed for flipping instruction, while Amro and Borup (2019), Oliveira and Pombo (2017), and West et al. (2017) focused on specific technologies important to BT - adaptive software, educational software, and videos for communication, respectively. While technology skills provide an essential foundation for BT, there is also a need for pedagogical skills. In their literature review, Oliver and Stallings (2014) included three broad skill categories to consider in designing BT. Lastly, Stevens and Rice (2016) provided some competencies for BT management through increased presence.

\section{Implementation Competencies}

The 10 articles in this final competency category presented competencies uncovered during implementing or transitioning to BT. While most of the articles focused on the skills that individual teachers need, Bingham (2016) and Sun and Gao (2019) reported the importance of clear roles for teachers, administrators, and other leaders in establishing school-wide BT. Competencies for individual teachers focused on overcoming barriers related to implementing BT. Such barriers included the lack of professional development or training for BT, the need for ongoing support, and managing the various aspects of BT, such as curriculum coordination between inperson and online spaces, student motivation inside and outside of the classroom, and technology problems (Akarawang et al., 2015; An, 2013; Riel et al., 2016). Zaka (2013) and de Araujo et al. (2017) focused on teachers' changing roles as a specific barrier to implementation and provided some guidelines for managing such changes. Basham et al. (2013) and Chen (2016) noted that one BT change is a heavier focus on motivating students by communicating with stakeholders at home or gathering student support for practices that place more ownership on them. Lastly, Ojaleye and Awofala (2018) discussed the importance of computer literacy as a prerequisite for BT implementation.

\section{BT Readiness and Evaluation}

Figure 9 illustrates the distribution of articles within the categories of measuring teacher perception of, readiness for, or performance within BT. These categories represent the 
Fig. 9 Categorization of Articles Focusing on BT Measurements and Evaluations

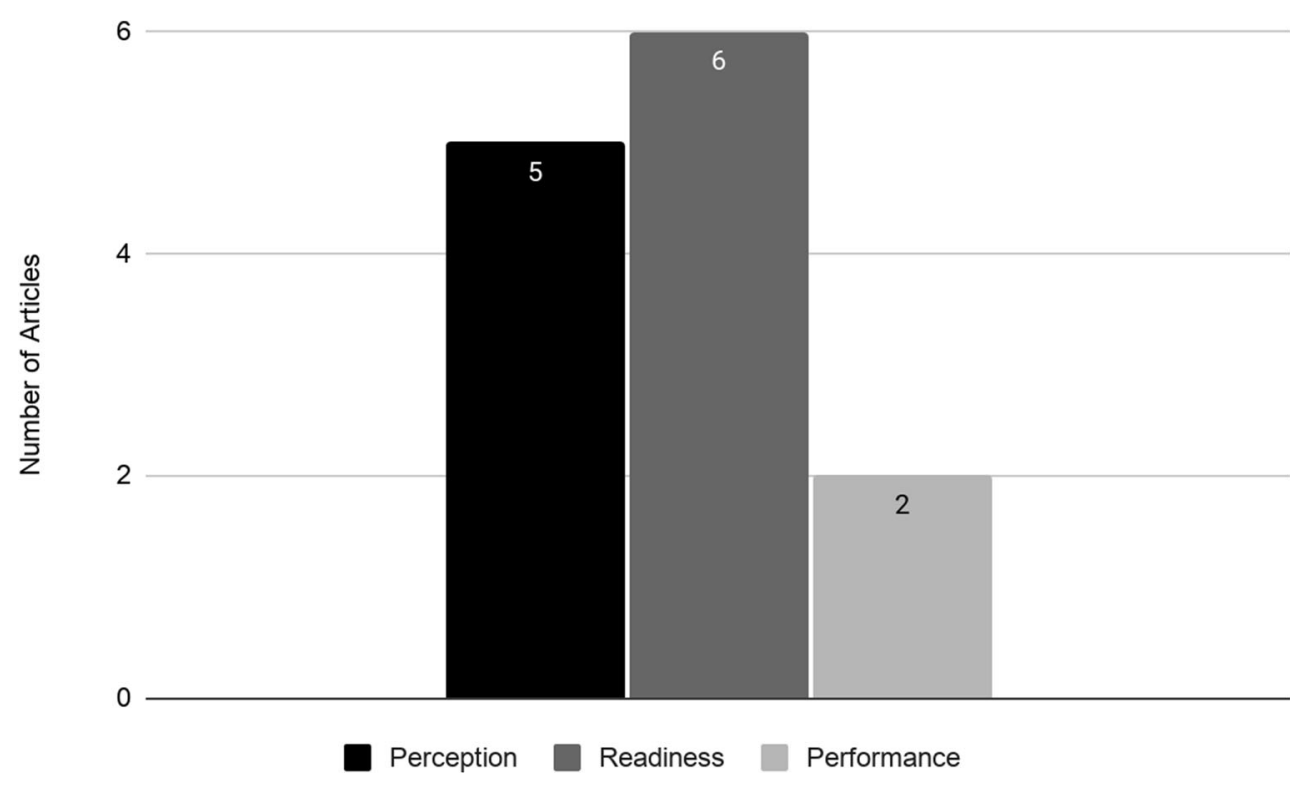

smallest of our review, hosting 13 articles total, but they are closely related to the previous category focused on competencies because most of the readiness and evaluation instruments sought to measure competencies or dispositions.

The five articles focused on measuring teachers' perceptions of BT included articles that measured in-service teachers' reactions to $\mathrm{PD}$ for BT and their own experiences using BT, and pre-service teachers' reactions to BT in their courses. In-service teachers generally had a positive perception of BT, recognizing its benefits to both themselves and their students (Al-Derbashi \& Abed, 2017; Alfahadi et al., 2015; Qasem \& Viswanathappa, 2016b). Pre-service teachers also generally reported positive perceptions of BT, stating that their experiences made them more likely to implement BT (Arnesen et al., 2019; Basal, 2015; EL-Deghaidy \& Nouby, 2008).

Six articles used various instruments to measure aspects of teachers' BT readiness. Graham et al. (2019), with follow-up validation work by Archibald et al. (2021), and Wong et al. (2016) analyzed teachers' dispositions toward aspects of BT, with Graham et al. (2019) providing additional measures regarding teachers' self-reported efficacy across four competency areas, and Wong et al. (2016) exploring the relationship between different dispositions. Other readiness instruments measured teachers' concern about implementing BT and whether prior experience or education affected teachers' BT readiness. Despite teachers' levels of concern or previous experiences, Hao and Lee (2016) and Kihoza et al. (2016) suggested that all teachers needed additional BT development. The need for help, regardless of perceived readiness, could be due to teachers claiming to be efficient in BT despite their deficiencies (Belmonte et al., 2019), which is likely a result of BT's social desirability (Parks et al., 2016).
The final two articles focused on measuring BT performance and related such measurements to $\mathrm{BT}$ preparation. Huett et al. (2011) used iNACOL's National Standard of Quality for Online Courses to evaluate online courses at a high school and blended courses at a middle school. They discovered that blended courses scored lower than the online courses in their evaluations and suggested the need for a separate metric for evaluating BT courses as well as the need for blended teachers to better understand BT course design. Anthony (2019) used her own evaluation metrics to observe, measure, and compare teaching practices and student performance across six BT elementary classes divided into three high-performing and three low-performing classes. There were five areas of differences between the two groups: (1) flexibility and responsiveness of the teacher, (2) using assessment in instructions, (3) engaging students, (4) clarity of the lesson's learning outcome, and (5) reinforcing and recognizing effort. The high-performing classes demonstrated more practices related to areas 1-3, while the lowperforming classes demonstrated more practices related to areas four and five. These differences suggest some pedagogical and management practices that teachers need to develop for BT.

\section{Discussion}

Due to geographical and publication location complexity, it was understandable that our literature search underwent many iterations. We noticed immediately that the articles we uncovered used many terms for "BT." While K-12 BT research seems to shy away from the term "hybrid," it was surprising to note how many articles did not appear in the search until "flip*" was added to the search terms. Flipped instruction was 
separated from searches for general BT articles, while other BT models, such as the Christensen Institute's (2021) rotation models, did not appear to impact the search results. Such findings could demonstrate a conceptual separation between general BT approaches and specific BT implementations like flipped instruction.

Within many international contexts, BT was referred to as information and communication technology (ICT) integration. For example, Karasavvidis (2009), our fourth most cited article, uses "ICT" throughout the article, only referencing the idea of a "blend" twice - once in the abstract and once in describing the context of their research. Similarly, Jimoyiannis et al. (2013) use "blended" throughout their article but not in their title or abstract. Given that $40.9 \%$ of our articles had international contexts, search term challenges are essential to overcome for anyone researching this area. It is imperative to include international research in reviews of K12 BT because they accounted for 15 of the 31 articles in our review published before 2016, providing a valuable foundation for the field.

Another challenge pertaining to BT literature is publication outlets. The articles in our analysis stemmed from 56 different journals, but only 14 of those published more than one article, and only five published more than two. This pattern is concerning for those seeking to publish K-12 BT preparation research and is further evidence of Graham's (2016) point that academic conversations centered on K-12 blended learning "are distributed across many disciplines and scholarly communities" (p. 28). While JOLR appeared to be a center for many publications, it did not appear in the list of top-cited publications. This phenomenon may partly be because JOLR is relatively new and has not yet been indexed by some major indices (e.g., Journal Citation Reports or Scimago Journal Rank). JOLR's top-cited publications in our review were Riel et al. (2016) with 27 citations, Parks et al. (2016) with 25, and Shand and Farrelly (2017) with 23 . These articles ranked 25th, 27th, and 28th for total citations and ranked 22nd, 26th, and 27th for citations per year, respectively. These rankings may illustrate that $J O L R$ is growing as a publication and that the journal may provide a more considerable impact in the future.

A final concern about K-12 BT preparation research is who is part of the conversation. As seen in Table 7, only 19 of the 183 authors in our review authored multiple articles. This trend suggests that most of the research in this field has been completed by those whose primary interests lay elsewhere. Relatively few articles directly focused on preparing K-12 teachers for BT. Most provided insights into BT preparation from either research that had a broader focus, such as Foulger et al.'s (2017) Teacher Educator Technology Competencies or Oliver and Stallings's (2014) review of BT literature across higher education and $\mathrm{K}-12$, or presented implications of BT preparation gleaned from BT implementation, such as the top- cited publications from Basal (2015) and Rosen and Beck-Hill (2012). The lack of research directly related to BT preparation highlights the need for more research across all thematic areas.

For example, there does not appear to be agreement on what should constitute BT competencies. Some competencies were based on adaptations of existing frameworks, such as Pulham and Graham's (2018) review or Huett et al.'s (2011) use of iNACOL's National Standard of Quality for Online Courses. Other competencies were presented as entirely new frameworks for use in PD or university coursework (AlDoseri et al., 2016; Bjekic et al., 2010) or as part of entirely new frameworks (Foulger et al., 2017). Research is needed to test the application of various competencies to BT preparation. Perhaps researchers could use readiness measurements described in the final section of our findings to measure how PD or coursework based on various competencies sets affect BT readiness. Such research could provide more descriptive and inferential research to the field as these methods were under-represented.

Other research opportunities also exist across each of the identified thematic areas. We intend to complete a deeper thematic review of all 88 articles to go beyond subject trends and focus on the articles' findings and remaining research gaps. There is also room for research exploring broader thematic gaps. For example, the flipped model seems to dominate other models in research about BT implementation. There is a need to uncover whether and how the implementation of other BT models differs from flipped instruction. There is also a need for research concerning university coursework and PD that goes beyond the limited timeframe in which teachers receive BT training. Research could focus on the long-term effects of PD in practice or of BT coursework upon entering the profession. Research could also identify best practices within PD and university coursework for BT.

\section{Conclusion}

This systematic review analyzed the research trends of 88 articles focused on preparing K-12 teachers for BT. We identified the most impactful articles and authors according to citation count, the most prolific journals, and the most common research methods. We additionally identified broad themes according to the articles' research questions and findings. Our analysis uncovered that a large percentage of research in K-12 BT preparation is from international resources, and that the largest publisher of K-12 BT preparation research is JOLR. Thematically, more articles focused on university coursework or professional development for BT preparation than on BT competencies; however, more research focused on BT competencies than on reviews, models, and theories for BT preparation or on assessments and measurements of BT readiness and performance. Additional research is needed to 
synthesize the findings of the articles in our review. There is also a need to determine the relationships between various forms of PD, coursework, and competencies and their effect on BT implementation and performance as well as whether implementation and preparation differ from one BT model to another.

Declarations The authors did not receive support from any organization for the submitted work. The authors have no conflicts of interest to declare that are relevant to the content of this article, though it was prepared as part of the primary author's dissertation. As this is a literature review, there were no human subjects and informed consent was not required.

\section{References}

Akarawang, C., Kidrakran, P., \& Nuangchalerm, P. (2015). Enhancing ICT competency for teachers in the Thailand basic education system. International Education Studies, 8(6), 1-8.

Al-Derbashi, K. Y., \& Abed, O. H. (2017). The level of utilizing blended learning in teaching science from the point of view of science teachers in private schools of Ajman Educational Zone. Journal of Education and Practice, 13.

Al-Doseri, M., Elgazzar, A., \& Nouby, A. (2016). A strategy for managing e-training environment's activities and its effectiveness in developing blended learning design competencies of Bahraini secondary stage female teachers. International Journal of Arts \& Sciences, $9(2), 1-16$

Alfahadi, A. M., Alsalhi, A. A., \& Alshammari, A. S. (2015). EFL secondary school teachers' views on blended learning in Tabuk City. English Language Teaching, 8(9), p51.

Amro, F., \& Borup, J. (2019). Exploring blended teacher roles and obstacles to success when using personalized learning software. Journal of Online Learning Research, 5(3), 229-250.

An, Y. (2013). Systematic design of blended PBL: Exploring the design experiences and support needs of PBL novices in an online environment. Contemporary Issues in Technology and Teacher Education (CITE Journal), 13(1), 61-79.

Anthony, E. (2019). (blended) learning: How traditional best teaching practices impact blended elementary classrooms. Journal of Online Learning Research, 5(1), 25-48.

Archambault, L., DeBruler, K., \& Freidhoff, J. (2014). K-12 online and blended teacher licensure: Striking a balance between policy and preparedness. Journal of Technology and Teacher Education, 22(1), 83-106.

Archibald, D. E., Graham, C. R., \& Larsen, R. (2021). Validating a blended teaching readiness instrument for primary/secondary preservice teachers. British Journal of Educational Technology, 52(2), 536-551. https://doi.org/10.1111/bjet.13060.

Arnesen, K. T., Graham, C. R., Short, C. R., \& Archibald, D. (2019). Experiences with personalized learning in a blended teaching course for preservice teachers. Journal of Online Learning Research, 5(3), 275-310.

Alayyar, G. M., Fisser, P., \& Voogt, J. (2012). Developing technological pedagogical content knowledge in pre-service science teachers: Support from blended learning. Australasian Journal of Educational Technology, 28(8), 1298-1316.

Azukas, M. E. (2019). Cultivating blended communities of practice to promote personalized learning. Journal of Online Learning Research, 5(3), 251-274.
Basal, A. (2015). The implementation of a flipped classroom in foreign language teaching. Turkish Online Journal of Distance Education, 16(4), 28-37.

Basham, J. D., Smith, S. J., Greer, D. L., \& Marino, M. T. (2013). The scaled arrival of K-12 online education: Emerging realities and implications for the future of education. Journal of Education, 193(2), $51-59$.

Belmonte, J. L., Sánchez, S. P., \& del Pino Espejo, M. (2019). Projection of the flipped learning methodology in the teaching staff of crossborder contexts. Journal of New Approaches in Educational Research (NAER Journal), 8(2), 184-200.

Bingham, A. J. (2016). Drowning digitally? How disequilibrium shapes practice in a blended learning charter school. Teachers College Record, 118(1), n1.

Bjekic, D., Krneta, R., \& Milosevic, D. (2010). Teacher education from elearner to e-teacher: Master curriculum. Turkish Online Journal of Educational Technology-TOJET, 9(1), 202-212.

Bromley, K., Faughnan, M., Ham, S., Miller, M., Armstrong, T., Crandall, C., Garrison, J., \& Marrone, N. (2014). Literature circles go digital. Reading Teacher, 68(3), 229-236. Aph.

Chen, L.-L. (2016). Impacts of flipped classroom in high school health education. Journal of Educational Technology Systems, 44(4), 411420 .

Christensen Institute. (2021). Blended learning models. Blended Learning Universe. http://www.blendedlearning.org/models/

Crawford, R., \& Jenkins, L. E. (2018). Making pedagogy tangible: Developing skills and knowledge using a team teaching and blended learning approach. Australian Journal of Teacher Education, 43(1), $127-142$.

Dabner, N., Davis, N., \& Zaka, P. (2012). Authentic project-based design of professional development for teachers studying online and blended teaching. Contemporary issues in technology and teacher education, 12(1), 71-114.

Daum, D. N., \& Woods, A. M. (2015). Physical education teacher educator's perceptions toward and understanding of K-12 online physical education. Journal of Teaching in Physical Education, 34(4), 716-724.

de Araujo, Z., Otten, S., \& Birisci, S. (2017). Mathematics teachers' motivations for, conceptions of, and experiences with flipped instruction. Teaching and Teacher Education, 62, 60-70.

Doğan, D., \& Gülbahar, Y. (2018). Using Facebook as social learning environment. Informatics in Education, 17(2), 207-228.

Donne, V. (2012). Wiki: Using the web connections to connect students. TechTrends: Linking Research and Practice to Improve Learning, 56(2), 31-36.

Drysdale, J. S., Graham, C. R., Spring, K. J., \& Halverson, L. R. (2013). An analysis of research trends in dissertations and theses studying blended learning. The Internet and Higher Education, 17, 90-100.

Duhaney, D. C. (2012). Blended learning and teacher preparation programs. International Journal of Instructional Media, 39(3), 197203.

EL-Deghaidy, H., \& Nouby, A. (2008). Effectiveness of a blended elearning cooperative approach in an Egyptian teacher education programme. Computers \& Education, 51(3), 988-1006.

Eisenbach, B. B. (2016). Considering the virtual classroom: A call to middle level education programs. Middle Grades Review, 2(1).

Foulger, T. S., Graziano, K. J., Schmidt-Crawford, D. A., \& Slykhuis, D. A. (2017). Teacher educator technology competencies. Journal of Technology and Teacher Education, 25(4), 413-448.

García-Sánchez, S., \& Santos-Espino, J. M. (2017). Empowering preservice teachers to produce ubiquitous flipped classes. Profile Issues in TeachersProfessional Development, 19(1), 169-185.

Goodnough, K., \& Murphy, E. (2017). The professional learning of grade six teachers of mathematics implementing the flipped classroom approach. Canadian Journal of Learning and Technology/La revue canadienne de l'apprentissage et de la technologie, 43(1). 
Graham, C. R. (2006). Blended learning systems: Definition, current trends, and future directions (pp. 3-21). Global Perspectives, Local Designs.

Graham, C. R. (2016). Reviewing the literature when there is so much of it. In C. D. Dziuban, A. G. Picciano, C. R. Graham, \& P. D. Moskal (Eds.), Conducting research in online and blended learning environments (pp. 28-42). Routledge.

Graham, C. R. (2019). Current research in blended learning. Handbook of Distance Education (4th Ed., pp. 173-188), 16.

Graham, C. R., Borup, J., Pulham, E., \& Larsen, R. (2019). K-12 blended teaching readiness: Model and instrument development. Journal of Research on Technology in Education, 51(3), 239-258.

Grant, M. J., \& Booth, A. (2009). A typology of reviews: An analysis of 14 review types and associated methodologies. Health Information \& Libraries Journal, 26(2), 91-108. https://doi.org/10.1111/j.14711842.2009.00848.x.

Graziano, K. J., \& Bryans-Bongey, S. (2018). Surveying the national landscape of online teacher training in $\mathrm{K}-12$ teacher preparation programs. Journal of Digital Learning in Teacher Education, 34(4), 259-277.

Greene, K., \& Hale, W. (2017). The state of 21 st century learning in the K-12 world of the United States: Online and blended learning opportunities for American elementary and secondary students. Journal of Educational Multimedia and Hypermedia, 26(2), 131159.

Gulosino, C. A., \& Miron, G. (2017). Growth and performance of fully online and blended K-12 public schools. Education Policy Analysis Archives, 25(124).

Hadjiathanasiou, P. (2009). The e-learning readiness of Cyprus primary teachers ahead of dias system integration into Cyprus schools. European Journal of Open, Distance and E-Learning, 1.

Halverson, L. R., Graham, C. R., Spring, K. J., \& Drysdale, J. S. (2012). An analysis of high impact scholarship and publication trends in blended learning. Distance Education, 33(3), 381-413.

Halverson, L. R., Spring, K. J., Huyett, S., Henrie, C. R., \& Graham, C. R. (2017). Blended learning research in higher education and K-12 settings. In M. J. Spector, B. B. Lockee, \& M. D. Childress (Eds.), Learning, design, and technology. Springer International Publishing.

Hao, Y., \& Lee, K. S. (2016). Teaching in flipped classrooms: Exploring pre-service teachers' concerns. Computers in Human Behavior, 57, 250-260.

Holland, D., \& Piper, R. (2016). High-trust leadership and blended learning in the age of disruptive innovation: Strategic thinking for colleges and schools of education. The Journal of Leadership Education, 15(2), 74-97.

Hoskins, B. (2011). Demand, growth, and evolution. Journal of Continuing Higher Education, 59(1), 57-60.

Hu, M., Arnesen, K., Barbour, M. K., \& Leary, H. (2019). A newcomer's lens: A look at K-12 online and blended learning in the journal of online learning research. Journal of Online Learning Research. 5(2).

Huett, K. C., Huett, J. B., \& Ringlaben, R. (2011). From bricks to clicks: Building quality $\mathrm{K}-12$ online classes through an innovative course review project. Online Journal of Distance Learning Administration, 14(5).

Jimoyiannis, A., Tsiotakis, P., Roussinos, D., \& Siorenta, A. (2013). Preparing teachers to integrate web 2.0 in school practice: Toward a framework for pedagogy 2.0. Australasian Journal of Educational Technology, 29(2).

Karasavvidis, I. (2009). Activity theory as a conceptual framework for understanding teacher approaches to information and communication technologies. Computers \& Education, 53(2), 436-444.

Kennedy, C. K., \& Hinkley, M. (2009). An evaluation of blending technology with pedagogy for teaching educators and its implication for their classroom teaching. International Journal of Web-Based Learning and Teaching Technologies, 4(2), 61-80.
Kihoza, P. D., Zlotnikova, I., Bada, J. K., \& Kalegele, K. (2016). An assessment of teachers' abilities to support blended learning implementation in Tanzanian secondary schools. Contemporary Educational Technology, 7(1), 60-84.

Krippendorff, K. (2004). Content analysis: An introduction to its methodology (2nd ed.). Sage.

Kundu, A. (2018). Blended learning in Indian elementary education: Problems and prospects. Journal of Online Learning Research, 4(2), 199-227.

Kurt, G. (2017). Implementing the flipped classroom in teacher education: Evidence from Turkey. Journal of Educational Technology \& Society, 20(1), 211-221.

Lee, Y. Y., \& Martin, K. I. (2019). The flipped classroom in ESL teacher education: An example from CALL. Education and Information Technologies.

Lewis, S., \& Dikkers, A. G. (2016). Professional development supports for the blended, co-taught classroom. Journal of Online Learning Research, 2(2), 103-121.

Lim, S. H. (2017). Teachers empowering teachers in an online community of practice: A case study of Korean EFL teachers' learning to teach flipped classroom on NAVER BAND. Multimedia-Assisted Language Learning, 20(1), 109-143.

Loncar, M., Barrett, N. E., \& Liu, G.-Z. (2014). Towards the refinement of forum and asynchronous online discussion in educational contexts worldwide: Trends and investigative approaches within a dominant research paradigm. Computers and Education, 73, 93-110.

Luo, T., Hibbard, L., Franklin, T., \& Moore, D. R. (2017). Preparing teacher candidates for virtual field placements via an exposure to K-12 online teaching. Journal of Information Technology Education: Research, 16.

Mishra, P. \& Koehler, M. (2006). Technological pedagogical content knowledge: A framework for teacher knowledge. Teachers College Record, 108(6), 1017-1054.

Moore, M., Robinson, H., Sheffield, A., \& Phillips, A. (2017). Mastering the blend: A professional development program for K-12 teachers. Journal of Online Learning Research, 3(2), 145-173.

Mouzakis, C. (2008). Teachers' perceptions of the effectiveness of a blended learning approach for ICT teacher training. Journal of Technology and Teacher Education, 16(4), 461-482.

Mouzakis, C., Roussakis, I., \& Tsagarissianos, G. (2010). A study of Greek teachers' satisfaction with the implementation of the European pedagogical ICT license pilot course. Teacher Development, 14(2), 189-205.

O'Sullivan, L., \& Seabra, N. M. (2016). School in a box in low resource primary school in Mozambique: Practical application of zone of proximal development in teacher training with mobile technology. International Journal of Mobile and Blended Learning, 8(2), 44-54.

Ojaleye, O., \& Awofala, A. O. A. (2018). Blended learning and problembased learning instructional strategies as determinants of senior secondary school students' achievement in algebra. International Journal of Research in Education and Science, 486-501.

Oliveira, A., \& Pombo, L. (2017). Teaching strategies mediated by technologies in the EduLab model: The case of mathematics and natural sciences. International Journal of Research in Education and Science, 3(1), 88-106.

Oliver, K. M., \& Stallings, D. T. (2014). Preparing teachers for emerging blended learning environments. Journal of Technology and Teacher Education, 22(1), 57-81.

Page, M. J., McKenzie, J. E., Bossuyt, P. M., Boutron, I., Hoffmann, T. C., Mulrow, C. D., Shamseer, L., Tetzlaff, J. M., Akl, E. A., Brennan, S. E., Chou, R., Glanville, J., Grimshaw, J. M., Hróbjartsson, A., Lalu, M. M., Li, T., Loder, E. W., MayoWilson, E., McDonald, S., et al. (2021). The PRISMA 2020 statement: An updated guideline for reporting systematic reviews. BMJ, 372, n71. https://doi.org/10.1136/bmj.n71. 
Papadakis, S., Dovros, N., Paschalis, G., \& Rossiou, E. (2012). Integrating LMSs in the educational process: Greek teachers' initial perceptions about LAMS. Turkish Online Journal of Distance Education, 13(4), 55-75.

Parks, R. A., Oliver, W., \& Carson, E. (2016). The status of middle and high school instruction: Examining professional development, social desirability, and teacher readiness for blended pedagogy in the southeastern United States. Journal of Online Learning Research, 2(2), 79-101.

Philipsen, B. (2019). A professional development process model for online and blended learning: Introducing digital capital. Contemporary Issues in Technology and Teacher Education, 19(4), 850-867.

Philipsen, B., Tondeur, J., Pareja Roblin, N., Vanslambrouck, S., \& Zhu, C. (2019a). Improving teacher professional development for online and blended learning: A systematic meta-aggregative review. Educational Technology Research \& Development, 67(5), 11451174.

Philipsen, B., Tondeur, J., Pynoo, B., Vanslambrouck, S., \& Zhu, C. (2019b). Examining lived experiences in a professional development program for online teaching: A hermeneutic phenomenological approach. Australasian Journal of Educational Technology, 35(5), 46-59.

Piotrowski, A., \& Witte, S. (2016). Flipped learning and TPACK construction in English education. International Journal of Technology in Teaching and Learning, 12(1), 33-46.

Puhala, J. J. (2018). Changing classroom practice: Elementary teacher experiences of a professional development program. Technology, Knowledge and Learning, 25(1), 129-147.

Pulham, E., \& Graham, C. R. (2018). Comparing K-12 online and blended teaching competencies: A literature review. Distance Education, 39(3), 411-432.

Pulham, E. B., Graham, C. R., \& Short, C. R. (2018). Generic vs. modality-specific competencies for K-12 online and blended teaching. Journal of Online Learning Research, 4(1), 33-52.

Qasem, A. A. A., \& Viswanathappa, G. (2016a). Blended learning approach to develop the teachers' TPACK. Contemporary Educational Technology, 7(3), 264-276.

Qasem, A. A. A., \& Viswanathappa, G. (2016b). Teacher perceptions towards ICT integration: Professional development through blended learning. Journal of Information Technology Education: Research, $15,561-575$.

Rieckhoff, B. S., Owens, R. F., \& Kraber, B. (2018). Teaching in the 21st century: Perspectives from a Catholic university partnership. Journal of Catholic Education, 21(2), 182-203.

Riel, J., Lawless, K. A., \& Brown, S. W. (2016). Listening to the teachers: Using weekly online teacher logs for ROPD to identify teachers' persistent challenges when implementing a blended learning curriculum. Journal of Online Learning Research, 2(2), 169-200.

Rosen, Y., \& Beck-Hill, D. (2012). Intertwining digital content and a oneto-one laptop environment in teaching and learning: Lessons from the time to know program. Journal of Research on Technology in Education, 44(3), 225-241.

Shaffer, S. (2016). One high school English teacher: On his way to a flipped classroom. Journal of Adolescent \& Adult Literacy, 59(5), 563-573.

Shand, K., \& Farrelly, S. G. (2017). Using blended teaching to teach blended learning: Lessons learned from pre-service teachers in an instructional methods course. Journal of Online Learning Research, $3(1), 5-30$
Shand, K., \& Farrelly, S. G. (2018). The art of blending: Benefits and challenges of a blended course for pre-service teachers. Journal of Educators Online, 15(1).

Song, Y., Jong, M. S., Chang, M., \& Chen, W. (2017). Guest editorial: "HOW" to design, implement and evaluate the flipped classroom?A synthesis. Journal of Educational Technology \& Society, 20(1), 180-183.

Stevens, M., Borup, J., \& Barbour, M. K. (2018). Preparing social studies teachers and librarians for blended teaching. Contemporary Issues in Technology and Teacher Education, 18(4), 648-669.

Stevens, M., \& Rice, M. (2016). Inquiring into presence as support for student learning in a blended learning classroom. Journal of Online Learning Research, 2(4), 447-473.

Sun, Y., \& Gao, F. (2019). Exploring the roles of school leaders and teachers in a school-wide adoption of flipped classroom: School dynamics and institutional cultures. British Journal of Educational Technology, 50(3), 1241-1259.

Turvey, K. (2010). Pedagogical-research designs to capture the symbiotic nature of professional knowledge and learning about e-learning in initial teacher education in the UK. Computers \& Education, 54(3), 783-790.

U.S. Department of Education (2017). Reimagining the role of technology in education: 2017 national education technology plan update.

Walta, C., \& Nicholas, H. (2013). The iPod touch in association with other technologies in support of a community of inquiry in offcampus teacher education. Australasian Journal of Educational Technology, 29(6).

Wayer, N., Crippen, K., \& Dawson, K. (2015). Design and enactment of online components during four blended learning courses. Journal of Online Learning Research, 1(2), 219-239.

Webel, C., Sheffel, C., \& Conner, K. A. (2018). Flipping instruction in a fifth grade class: A case of an elementary mathematics specialist. Teaching and Teacher Education, 71, 271-282.

West, R. E., Jay, J., Armstrong, M., \& Borup, J. (2017). "Picturing them right in front of me": Guidelines for implementing video communication in online and blended learning. TechTrends: Linking Research and Practice to Improve Learning, 61(5), 461-469.

Wong, K. T., Hamzah, M. S. G., Goh, P. S. C., \& Yeop, M. A. B. (2016). Blended e-learning acceptance as smart pedagogical tools: An initial study in Malaysia. Turkish Online Journal of Educational Technology-TOJET, 15(4), 25-31.

Zaka, P. (2013). A case study of blended teaching and learning in a New Zealand secondary school, using an ecological framework. Journal of Open, Flexible, and Distance Learning, 17(1), 24-40.

Zhang, Z. (2010). Using online action research to improve a teacher education course. Ontario Action Researcher, 11(1).

Zhou, W., Yasuda, T., \& Yokoi, S. (2007). Supporting lifelong learning in the information age. Journal of College Teaching \& Learning (TLC), 4(9).

Ziegenfuss, D., Furse, C., Sykes, E., \& Buendía, E. (2019). Beyond the click: Rethinking assessment of an adult professional development MOOC. International Journal of Teaching and Learning in Higher Education, 31(1), 63-72.

Publisher's Note Springer Nature remains neutral with regard to jurisdictional claims in published maps and institutional affiliations. 